International Journal of Geography and Geography Education (IGGE)

To cite this article: Saed, M. N. S., Faqe, G. R. \& Rasul, A. (2019). Water quality effects on kidney diseases in the slums area of Erbil city, Iraq. International Journal of Geography and Geography Education (IGGE), 40, 406-414.

\title{
WATER QUALITY EFFECTS ON KIDNEY DISEASES IN THE SLUMS AREA OF ERBIL CITY, IRAQ
}

\author{
Saadaldeen Muhammad Nuri SAED ${ }^{1}$
}

Gaylan Rasul FAQE

Azad RASUL

\begin{abstract}
Many cities in the world are facing a quick inhabitant growth of slum areas while the detailed information about this issue is lacking. The study aim is an identification of the spatial correlation between the quality of water and kidney disease. A sample of 94 specimens was collected for different areas of the random areas to confirm the existence of cases of kidney disease in addition to a set of environmental, social and cultural characteristics related to some aspects affecting their healthy life. The chemical characteristics of drinking water in the study area were compared with the characteristics of the World Health Organization. The correlation between some chemical properties of water and especially related diseases (kidney) assessed. The research find correlation between the value of potential of Hydrogen $(\mathrm{pH})$ and kidney disease spread in the study area $\left(R^{2}=0.65 ; P<0.01\right)$ and we found correlation between Electrical conductivity $(E C)$ and renal disease $\left(R^{2}=0.85 ; P<0.01\right)$. The highest correlation was found between Magnesium lon $\left(\mathrm{Mg}^{2+}\right)$ and kidney disease $\left(\mathrm{R}^{2}=0.94, \mathrm{p}<0.01\right)$. We found the relationship with Nitrate $\left(\mathrm{NO}_{3}^{-}\right)$has a strong direct relationship and within a strong statistical significance $\left(R^{2}=0.86, p<0.01\right)$. We also found a moderately positive and statistically significant correlation between sulfate $\mathrm{SO}_{4}^{-2}$ and kidney disease prevalence $(\mathrm{R} 2=0.57, \mathrm{P}<0.01)$.
\end{abstract}

Keywords: Kidneys Disease, Slum Area, Water Quality, WHO Standards, Spatial Correlation 


\section{INTRODUCTION}

One of the major consequences of urbanization is that it is most prominent in developing countries; the persistence and rise in informal settlements including slums. While such terms are not synonymous, these and similar settlement types are part of the wider urbanization process which facilitates allow their residents extra-legal access to housing, land, infrastructure, services, and economic activity (Jones, 2017). Slums area is a worldwide phenomenon that has widespread in all countries, particularly countries that are in a problematic situation because of wars or other factors (Jones, 2017). United Nation refers to the slum area as an urban area with overpopulation, unhealthy infrastructure, unsafe water quality and poor morphometric of housing (Jones, 2017). Furthermore, UN-Habitat estimates that about 863 million people lived in areas of the slum with low-middle profits (Al, Engineering and Mobile, 2018). Since 1996, the number of people without access to safe water in urban areas was rising sharply in developing countries as a result of rapid urbanization, much of which was occurring in peri-urban and slum areas (Kimani-Murage and Ngindu, 2007).

Many cities in the world are facing a quick inhabitant growth of slum areas while the detailed information about this issue is lacking (Kuffer et al., 2017). In the $21^{\text {st }}$ century, both urbanization and health equity are two of the main challenge concepts for environmental condition (Egondi et al., 2013). Health inequalities can be avoided in the social, ecological and political situations that constitute disease and mortality, and excessively affect immigrants, ethnic, and religious groups (Corburn, 2017). Environment contamination is among the main worldwide threats for mortality and responsible for increased risk for diseases. The most noticeable disasters occur in these informal areas due to they being situated in marginal areas (Richmond, Myers and Namuli, 2018). Swahn, Palmier, Kasirye and Yao (2012), mentioned that a worldwide mortality ratio of sixteen per 100,000 , or one death every 40 seconds, is a major public health problem.

Slums in Iraq began in many cities, especially Baghdad and Najaf in the 1850s (Al-Madi, 2018). Nowadays, the number of slum area in whole Iraqi governors aggregate to 1552 informal settlements. Hundreds of thousands of Iraqis resident in "slum area"; informal settlements organised from poor housing. Thus, they face a lack of main facilities such as schooling, discarding of sewage, electricity, and water quality (Ana, 2012).

Kidneys disease is one of the global public health diseases in both developing and developed countries and creates a major risk factor for human health. About $9,6 \%$ of non-institutionalized US adults are estimated to have kidney problems. Also, studies in Asia, Europe, and Australia confirm the great dominance of kidney diseases (Levey et al., 2007). Lowincome and environmental exposure has a significant impact on health behaviours which donate to health deficiency; the poor are more vulnerable to disease due to the absence of access to facilities like water quality, sanitation and sufficient nutrition (Garcia-Garcia et al., 2014). There are several factors causing kidney diseases such as unpredictable environmental poisons, groundwater drinking, escalation of heavy material in $\mathrm{H}^{2} \mathrm{O}$, high fluoride levels and potential effects of AIFx in soil and water as well as a genetic and social feature (Wasana, Aluthpatabendi, Kularatne, Wijekoon, Weerasooriya and Bandara, 2016).

Despite the great need for sanitation improvements in slums, there has been limited progress. The factors limiting sanitation progress include low-prioritization by stakeholders, inadequate funding, implementation of inappropriate (unsustainable) technologies, and difficulties of shared responsibilities (Isunju, Schwartz, Schouten, Johnson and Van Dijk, 2011). To the best ofour knowledge, no work has been conducted on the healthcare among slum areas in the study area. This was then conducted to evaluate the health among slums area in Erbil City-Iraq.

\section{MATERIALS AND METHODS}

\section{Study area}

The study site covers Erbil city which is located in the Northern part of Iraq serving as the center of the Iraq. It sites within the latitudes and the longitudes of $36^{\circ} 080 \mathrm{~N}-36^{\circ} 140 \mathrm{~N}$ and $43^{\circ} 570 \mathrm{E}-44^{\circ} 030 \mathrm{E}$ (Figure 1). It is situated $412 \mathrm{~m}$ above sea level (Rasul, Balzter, Ibrahim, Hameed, Wheeler, Adamu and Najmaddin, 2018). The evaluated population of Erbil governorate was about 1,500,000 inhabitants according to the census of 2015. Erbil city is characterised by two types of weather as it is wet and cold in the winter, which lasts from mid-October to early March, and hot and dry summer which begins from the end of April to the end of September. According to Erbil weather station, the rates of precipitation have decreased recently. This is due to global warming changes (Faqelbrahim, 2013).Occasional drought seasons that are repeated over periods of time lead to underground water recharge deficiency. A significant amount of rainfall as well as cold temperatures characterizes the spring seasons (Faqelbrahim, 2017). The principal $\mathrm{H}^{2} \mathrm{O}$ source in the study area is groundwater, which is relying on an unconfined aquifer. However, after 2010, most of the study site has been reliant on the water project that is running from the Great Zab River, which is situated around $32 \mathrm{~km}$ to the west of the city (Hameed, Faqelbrahim, Sherwan and Hidyat, 2015). 


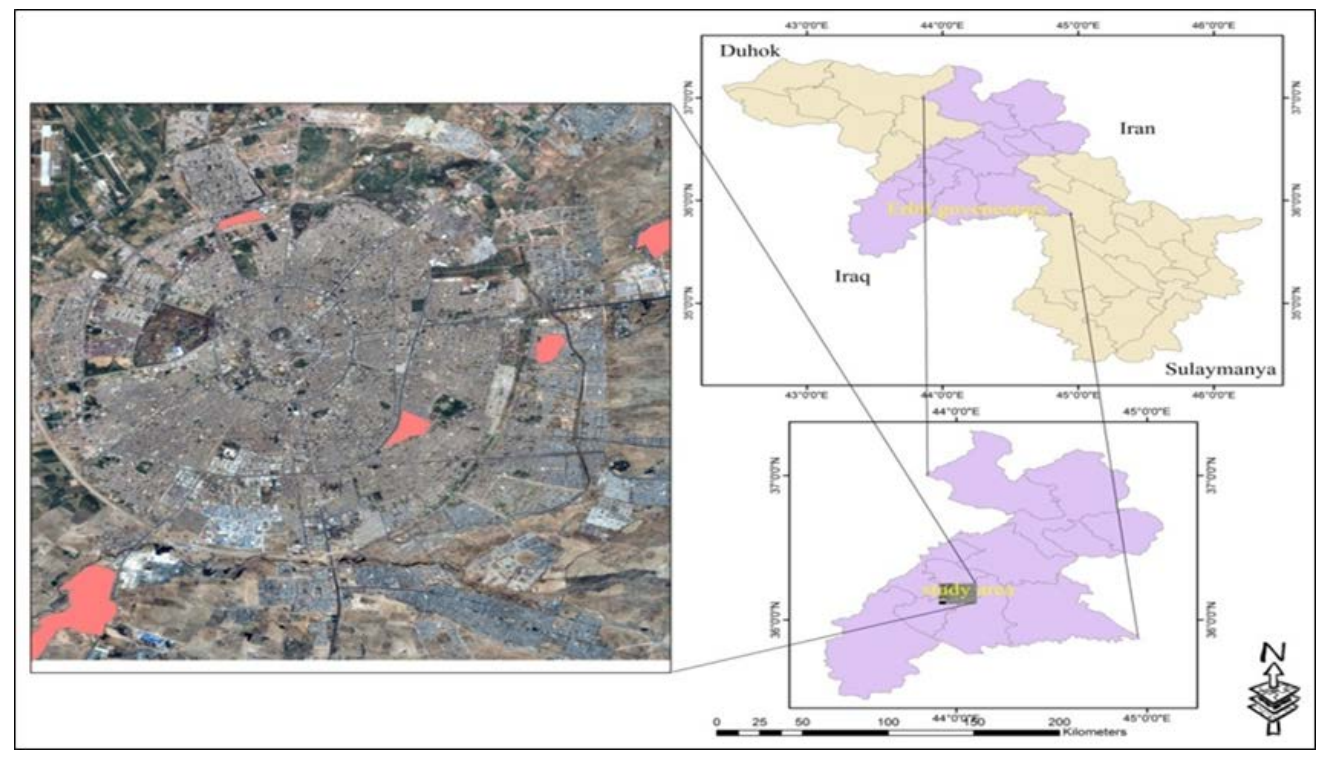

Figure 1: Study Area (Erbil city)

\section{Data}

The study adopted interviews and surveys for collecting information. The survey involved questions (open-ended questions) about particular slums characteristics. To arrest the fundamental information of slums various contexts, the study analyzed the spatial distribution of the four random areas. A content analysis was used to classify the responses by examining all answers to improve a range of public matters that often appeared in their answers. Afterward, we counted the number of responses that reported to each issue. The issue of basic services including socio-economic, health culture, environmental, culture, and purity of drinking water was mentioned by the 94 forms within the people who live in the slum area.

\section{METHOD}

\section{Questioners}

One of the sources of the study was the data obtained from the fieldwork through the distribution of 95 questionnaires. The form consists of four sets of questions, the second group includes questions about drinking water, water storage and cleaning (the source of drinking water, the presence of the filter on the pipes, the age of the water network, the sense of the taste of chlorine and other salts, or changing the characteristics of the water as color and water). The third group of questions is questions about diseases among the population and the way and place of treatment. The fourth and final group are some questions about the degree of the citizen's culture in dealing with water and the environment and the extent of health culture. Appendix (A) illustrates the unhealthy and environmental condition of a slum area. Appendix (B) Questionnaire form.

\section{Water quality}

The second source of information on water in the study area is the official figures and statistics in the General Directorate of Health of Erbil, the Directorate of Health Supervision Affairs, the Food Control Division, the Food Control Division, the Department of Quality Control and the Chemical and Bacteriological Tests. In the research, 42 samples of wells and houses to determine the degree of purity for the period (20/1 / 2017-2 / 2/2018) as follows: 17 samples of water wells and tub in Turaq district. 17 samples of water wells in Sebardan neighborhood and 3 samples of water wells Hasaruk neighborhood and 5 sample of water wells and houses Sarkarez.

\section{Correlation coefficient}

Pearson correlation coefficient is a dimensionless measure that determines a linear relation between two variables. From the Pearson correlation coefficient, Pearson (R) is used to measure the correlation between quantitative variables. This 
is a distinction from the Spearman coefficient, which is used to measure the correlation between ordinal variables. The Pearson coefficient can be calculated using one of the following equations:

$$
\begin{array}{r}
r=\frac{\sum_{i}^{n}=1(X i-\bar{X})(Y i-\bar{Y})}{\sqrt{\sum_{\mathrm{i}}^{\mathrm{n}}=1(X i-\bar{X})^{2}} \sqrt{\sum_{i=1}^{n}\left(Y i_{\mathrm{i}} \bar{Y}\right)^{2}}} \quad \text { (1) } \\
r=\frac{N \sum X Y-\left(\sum X\right)-\left(\sum Y\right)}{\sqrt{\left.N \sum X^{2}-\left(\sum Y\right)\right)^{2}} \sqrt{\left.N \sum Y^{2}-\left(\sum Y\right)\right)^{2}}}
\end{array}
$$

We can judge whether the correlation coefficient is a real correlation, or that it is a result of the chance factor, which is statistically tested by (t-test), especially since the frequency distribution of the Pearson correlation coefficient is normal and we can draw confidence limits and test it at the moral levels required, like any other statistical feature

$$
t=\frac{r}{\sqrt{1-r^{2}}} \sqrt{n-2}
$$

The correlation coefficient $(t)$ is defined as the interpretation coefficient, which denotes the ratio of the common variation of the variables interpreted by the relationship between them. The coefficient of the correlation coefficient ( $t$ ) is defined by the explanatory factor, which calls the ratio of the common variation of the variables explained by the relationship between them (Shehada, 2011).

\section{RESULTS}

\section{Water Quality in the Study Area}

In the northern part and north-east, the boundaries of the municipality of Erbil begin to rise $425 \mathrm{~m}$, and in the east begins to rise up to $445 \mathrm{~m}$ and to reach the minimum level $375 \mathrm{~m}$ in the neighborhood of Turq.

Sewage waste is one of the main sources of pollution inside and outside cities because it contains toxic substances that are difficult to decompose. Most of the waste products are toxic substances, heavy metals, organic chemicals, bacteria and viruses. The use of these wastes for agricultural purposes in the areas that are located within the tertiary zone and are used continuously throughout the year, especially in the area of vegetable cultivation, which are used as daily food for the city's population. The population in these areas is in direct contact with the polluted environment. RC effects on the earth and man and is no doubt that the weakness of the administrative authorities has an important role in this aspect in addition to poor health and environmental culture of the population in these areas.

\section{Compare Water Quality in The Study Areas With Global Standards}

The $\mathrm{pH}$ values of all wells comply with Iraqi standards and, the World Health Organization (WHO) standards for potable water quality. This is due to the nature of the aquifer and the natural balance in the water. Nitrates are an indicator of water pollution, and nitrate pollution is a global problem. WHO has identified nitrate water pollution as an agricultural and sewage intrusion, which in turn affects human health. Nitrate is one of the most important factors affecting health, as the high concentration of nitrate ion resulting from the reduction of nitrates in the human body has a negative effect for two reasons:

A - nitrite is able to reduce hemoglobin blood to the compound of hemoglobin (one of the qualities found in the blood naturally with a small concentration), but in the case of exposure to high doses of nitrite or nitrate reduced to nitrite, the proportion of hemoglobin rises in the blood and is exposed to symptoms in the condition of the high rate to $30-40 \%$ shows the body features choking that may lead to death (Al-Khuzaie, 2014)

B- Under certain chemical conditions, nitrite ions may interact with amines and amides in the human body and convert them into nitrazine compounds, some of which have a carcinogenic effect (Al-Khuzaie, 2014)

According to data from the Ministry of Health and Erbil Health Department, most of the water wells in the slum area comply with international standards, except for the district of Turq, which reached $54.64 \mathrm{mg} / \mathrm{L}$, while the standards of the World Health Organization is $50 \mathrm{mg} / \mathrm{L}$, and it was found that wastewater has negatively affected the high proportion of nitrates. The relative decrease in nitrates in other regions is due to the fact that the groundwater level is deep. Soluble solids affect water soaking and help microorganisms growth. Water is well tolerated when the average concentration of total dissolved solids (TDS) is less than $600 \mathrm{mg} / \mathrm{L}$. In comparison to international standards, it has not exceeded but there is a relative increase in the region Sarkarez while the district Turaq is below the level. 
Chloride in drinking water is generally not harmful to humans except in high concentrations, however, it may be harmful to people with heart or kidney disease (Ramlawi, 2013). The results of the study indicate that the average concentration of chloride in the study area between 11-15 PPM. The Jadoon, study of some neighborhoods in Erbil has yielded similar results. The Ca results of the analysis indicate that the average concentration of the calcium element in the study area is consistent with the Iraqi standards and the criteria of the Iraq of Iraq in addition to the standards of the WHO. The increase of the element of magnesium in the groundwater affects the health of humans, especially the safety of the intestines (Figure 2).

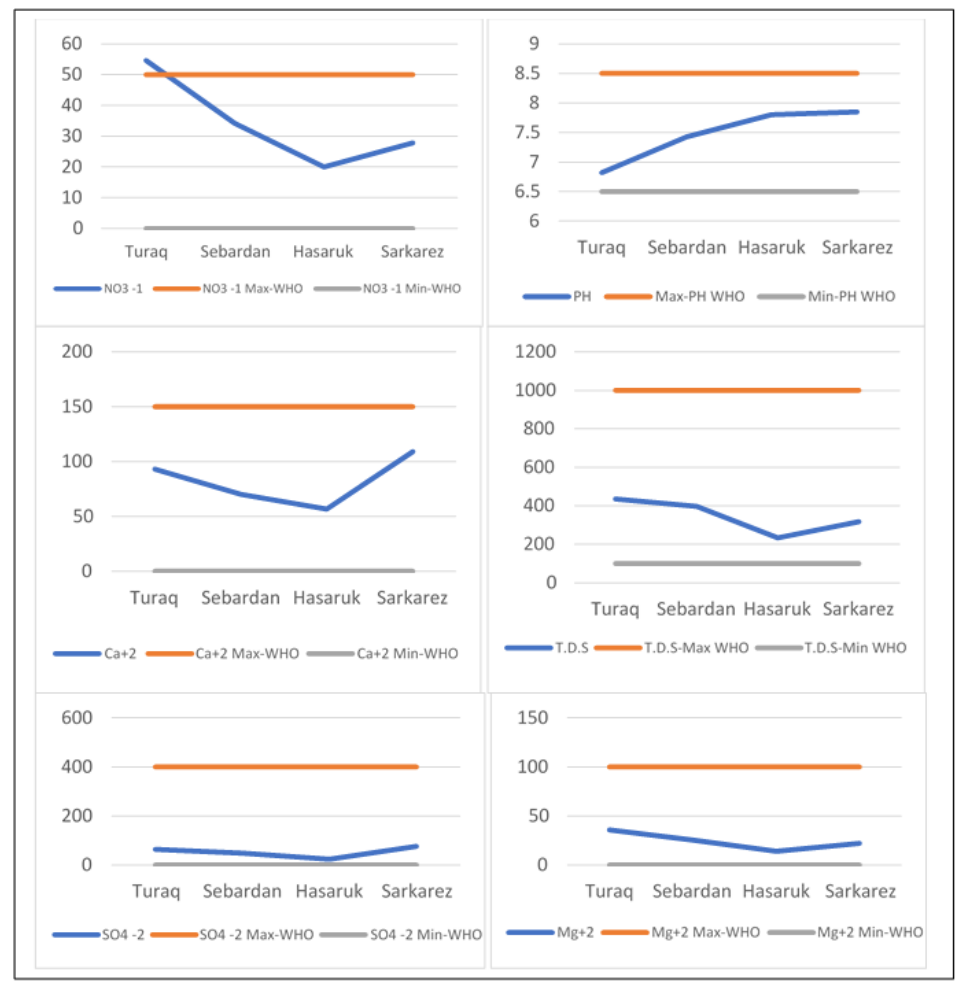

Figure 2: Compare Water Quality in the Study Areas With Global Standards

\section{Kidney Diseases in the Study Area}

Through analysis the answers of the questioners, we find that many family members have diseases such as Weak Kidneys, Kidney Stones and Sand Kidneys as well as Blood pressure and Diarrhea with Blood. This is the natural result of a random residential neighbourhood such as Turaq due to the geographical location, bad environmental location of the neighborhood, and the increase in the proportion of harmful substances in water such as nitrates and irregular use of chlorine. Besides it is clear that the category "under 25years" is more susceptible to the disease, especially children and young people.

\section{Correlation Between Chemical Characters of Water and Kidney Diseases}

It was found that there was a strong inverse relationship with a strong statistical significance between the value of potential of Hydrogen $(\mathrm{pH})$ and kidney disease spread in the study area $\left(R^{2}=0.65 ; P<0.01\right)$.A strong and statistically significant correlation $\left(R^{2}=0.85 ; P<0.01\right)$ was found between Electrical conductivity $(E C)$ and renal disease (Figure 3$)$. As a result of changing the chemical characteristics of potable water, especially in some residential areas, the relationship varies according to the geographic location of the slum area. The study also found a strong positive relationship with a strong statistical significance, between thorium (Th) and the prevalence of kidney disease $\left(R^{2}=0.85 ; P<0.01\right)$. In addition, there was a moderate significant positive relationship with $\mathrm{Ca}^{+2}\left(R^{2}=0.44, p<0.01\right)$. 


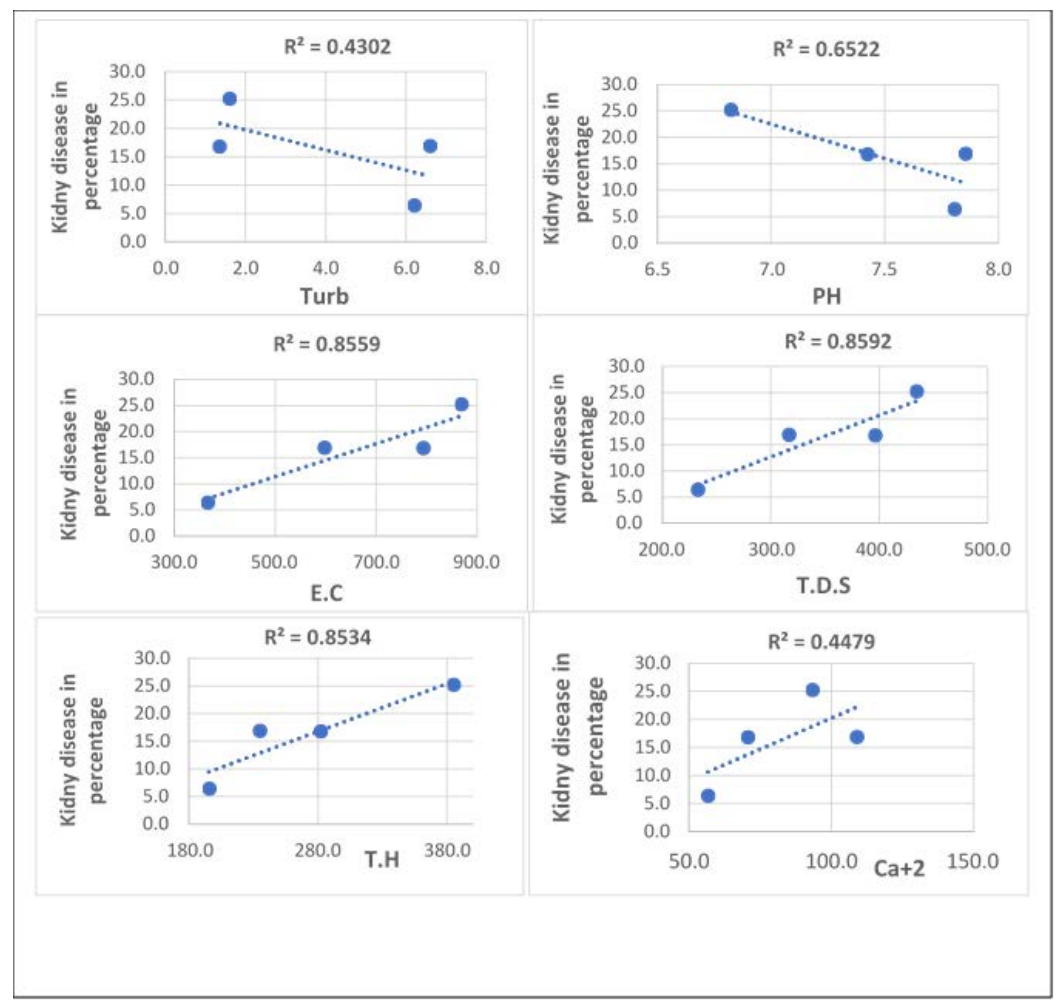

Figure 3: Relationship Between the Elements (Tur, PH, EC, TDS, Th, Ca + 2) and Kidney Disease

The results showed that the highest correlation $\left(R^{2}=0.94, p<0.01\right)$ was found between Magnesium lon $\left(\mathrm{Mg}^{2+}\right)$ and kidney disease (Figure 4).The relationship with $\mathrm{NO}_{3}^{-}$has a strong direct relationship and within a strong statistical and moral significance $\left(R^{2}=0.86, p<0.01\right)$. There is a moderately positive and statistically significant correlation between $\mathrm{SO}_{4}^{-2}$ and kidney disease prevalence $\left(R^{2}=0.57, P<0.01\right)$. However, the relationship between kidney-related diseases and chemical properties is weak.

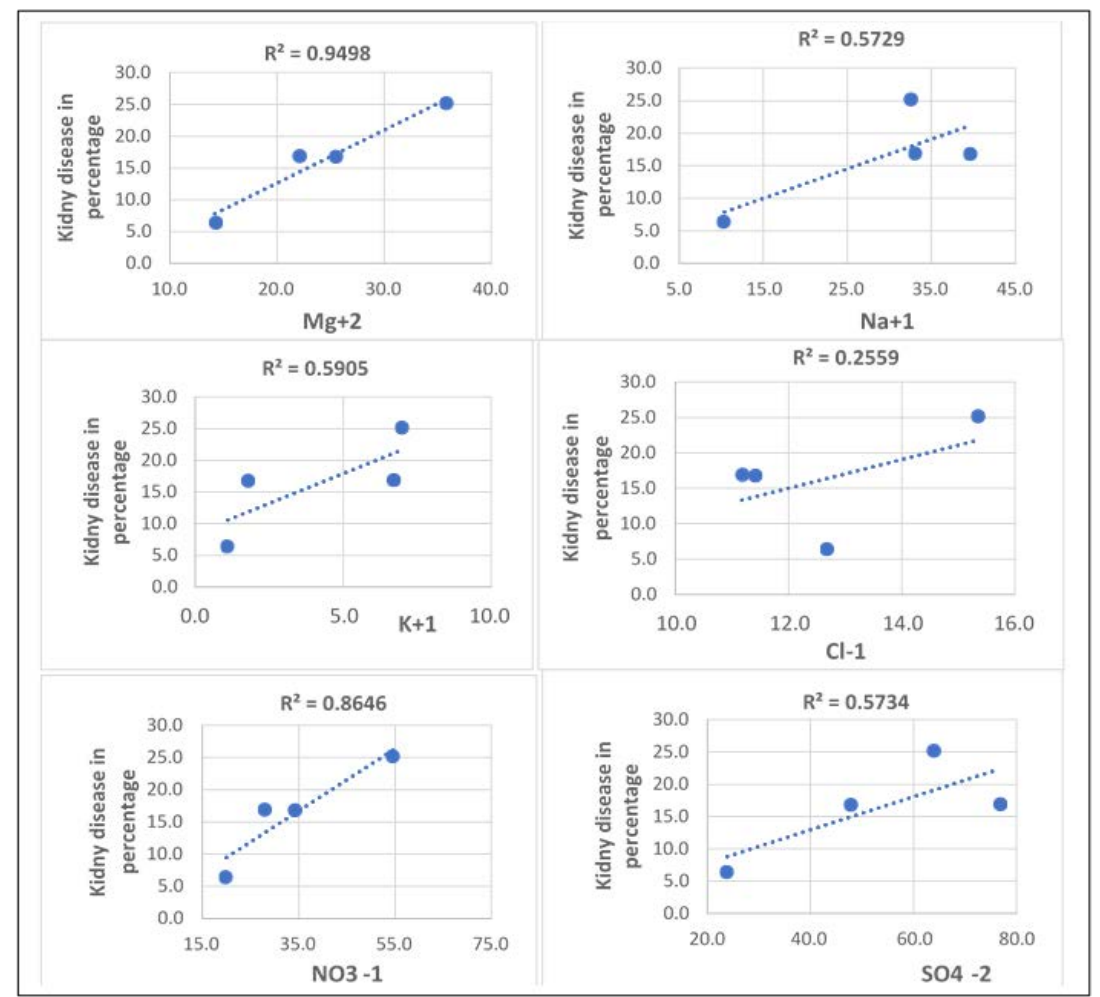

Figure 4: The Relationship Between the Elements $\left(\mathrm{Mg}^{2+}, \mathrm{Na}^{+1}, \mathrm{~K}^{+1}, \mathrm{Cl}^{-1}, \mathrm{NO}_{3}^{-}, \mathbf{S O}_{4}^{-2}\right)$ and Kidney Disease 


\section{DISCUSSION}

The problem of random areas is a global problem, but the nature of this problem varies from one country to another and from one society to another. In this research, one aspect was highlighted: the spread of kidney diseases among the population of the research area, and the investigation of the purity of water and its impact on public health. In addition, the research focused on the heavy waterways and their environmental effects, and the subject needs a lot of research and within a range of disciplines in order to cover all aspects of the population of these areas such as (social, economic, administrative and psychological).

The study of the subject of sewage and its effects on the environment and the concentration of some elements, which are concentrated high percentage of nitrates, chlorine, sodium, magnesium and phosphorus (Saleh Hussein, 2010). The study on the quality of water and its impact on human health in the United Arab Emirates, which focused on drinking water, groundwater and sewage, he stressed that the use of wastewater, especially those that produce agricultural crops, concerns about the possibility of the transmission of genotypes to crops are reflected in the health status of the population. Our result concurs with Hala (2013) that close connection between underground wells with chemical elements, especially chloride and nitrate, where it is increasing in areas suffering from poor drainage networks, especially in areas where there is a high number of kidney failure cases. The research found the number of injuries in the Gaza governorates was $33.3 \%$, and there is a strong correlation between the high rates of nitrates with kidney failure.

\section{CONCLUSIONS}

The aim of the research was to find out the size, number and type of disease cases in some random or informal areas of Erbil city with a focus on kidney-related diseases such as kidney weakness, kidney sand, kidney stones. We used the figures and data of the Ministry of Health and the numbers of the Department of Quality Control, and access to the properties of wells for the neighborhoods of Arbil.

The results showed that the values of the characteristics of drinking water were consistent with the WHO criteria with an exception in the $\mathrm{NO}_{3}^{-}$property because the results indicated that there was superior to the WHO standards. Also, TDS it is in line with international standards. We found Correlation between the value of $\mathrm{pH}$ and kidney disease spread in the study area $\left(R^{2}=0.65 ; P<0.01\right)$ correlation between $E C$ and renal disease $\left(R^{2}=0.85 ; P<0.01\right)$. The highest correlation was found between $\mathrm{Mg}^{2+}$ and kidney disease $\left(\mathrm{R}^{2}=0.94, \mathrm{p}<0.01\right)$. We also found the relationship with $\mathrm{NO}_{3}^{-}$has a strong direct relationship $\left(R^{2}=0.86, p<0.01\right)$.

The research focused on water quality and the prevalence of kidney disease. The research did not shed light on some of the paragraphs that relate directly and sometimes indirectly to the use of the water storage method which already in the questionnaire, as well as the aspect of the health and environmental culture among the population. One of the obstacles that affected the course of the research relates to the difficulty of obtaining real numbers, and sometimes the discrepancy in the numbers to some quarters. Some data is monopolized as data that touches the security aspect and requires mediation to obtain it. The main recommendations for future research are to focus on some elements of the population that have negative impacts in rural and urban areas, where poor and marginalized communities are concentrated and suffer from weak services.

Author Contributions: Data curation, S.S.; Formal analysis, S.S.; Investigation: G.F.\&S.S.; Methodology, G.F.\& S.S. \& A.R.; Resources, G.F.; Validation, G.F.; Visualization, A.R. \&S.S.; Writing-original draft, G.F.; Writing-review \& editing, S.S.\& G.F.\&A.R.

Funding: Please add: This research received no external funding.

Conflicts of Interest: The authors declare no conflict of interest.

\section{References}

Al-Khuzaie, D. (2014). The chemical and physical properties common in the region and the assessment of their suitability for irrigation. Basra - Iraq, Basra Research Journal, 40, 2.P 1-9.

Al-Madi, W. (2018). Study of the random areas of the city of najaf during ten years (2003-2013) by geographic information systems', International Journal of Advanced Engineering and Management Research, 3(1), 11-23.

Ana, N. (2012). Iraqi Slums: myths and solutions. Retrieved 18 May 2018, from https://www.ncciraq.org/en/archive/op-eds/item/231iraqi-slums-myths-and-solutions.

Corburn, J. (2017). Urban place and health equity: Critical issues and practices.International Journal of Environmental Research and Public Health, 14(2), 1-10. 
Egondi, T., Kyobutungi, C., Ng, N., Muindi, K., Oti, S., Vijver, S., \&Rocklöv, J. (2013). Community perceptions of air pollution and related health risks in Nairobi slums. International Journal of Environmental Research and Public Health, 10(10), 4851-4868.

Faqelbrahim, G. (2013).Urban Expansion Monitoring in Erbil City. Utilizing Remote Sensing tools in the Kurdistan Region.(Master thesis, Sheffield Hallam University).Retrieved fromhttps://www.grin.com/document/311575

Faqelbrahim, G. (2017). Urban land use land cover changes and their effect land surface temperature: case study using Dohuk city in the Kurdistan region of Iraq,Climate, 5(1), 2-18.

Garcia-Garcia, G., Jha, V., Tao Li, P. K., Garcia-Garcia, G., Couser, W. G., Erk, T.,\&Osafo, C. (2014). Chronic kidney disease (CKD) in disadvantaged populations.Clinical Kidney Journal, 8(1), 3-6.

Hala, M. (2013).Chronic kidney failure in the governorates of Gaza, a study in medical geography..(Master of Geography, Islamic University of Gaza).

Hameed, H. M. Faqelbrahim,SherwanS. Q. \& Hidyat H. (2015). Impact of urban growth on groundwater levels using remote sensing case study: Erbil city, Kurdistan region of Iraq'.Journal of Natural Sciences Research, 5(18), 72-85.

Isunju, J. B., Schwartz, K., Schouten, M. A., Johnson, W. P. \& Van Dijk, M. P. (2011). Socio-economic aspects of improved sanitation in slums: a review. Public health, 125(6), 368-376.

Jones, P. (2017). Formalizing the informal: Understanding the position of informal settlements and slums in sustainable urbanization policies and strategies in Bandung, Indonesia. Sustainability, 9(8), 1436.

Kimani-Murage, E. W.\&Ngindu, A. M. (2007). Quality of water the slum dwellers use: the case of a Kenyan slum. Journal of Urban Health, 84(6), 829-838.

Kohli, D. (2015).Identifying and classifying slum areas using remote sensing.(PHD. Desertation, university of Twente, Holland).

Kuffer, M., Pfeffer, K., Sliuzas, R., Baud, I.\&Maarseveen, M. (2017).Capturing the diversity of deprived areas with image-based features: The case of Mumbai. Remote sensing, 9(4), 384.

Levey, A. S., Atkins, R., Coresh, J., Cohen, E. P., Collins, A. J., Eckardt, K. U.,\&Powe, N. R. (2007). Chronic kidney disease as a global public health problem: approaches and initiatives - a position statement from kidney disease improving global outcomes. Kidney International, 72(3), 247-259.

Ramlawi ,A.(2013),Assessment of the Desalinated Water Used in Household facilities in Gaza Strip, Imaster thesis(Mediterranean agronomic Institute, Chania.

Rasul, A., Balzter, H., Ibrahim, G., Hameed, H., Wheeler, J., Adamu, B., \& Najmaddin, P. (2018) 'Applying Built-Up and Bare-Soil Indices from Landsat 8 to Cities in Dry Climates', Land, 7(3),81. doi: 10.3390/land7030081.

Richmond, A., Myers, I. and Namuli, H. (2018) 'Urban Informality and Vulnerability: A Case Study in Kampala, Uganda', Urban Science, 2(1), p. 22. doi: 10.3390/urbansci2010022.

Saima Jadoon, Sarfaraz Munir, Iftikhar Fareed,( 2015) Evaluation of Drinking Water Quality in Erbil City Kurdistan, Region-Iraq, Journal of Environment and Earth Science, Vol.5, No.21

Saleh Hussein, (2010). Effect of Lactation on the Haemogram and Certain Blood Constituents of the Dromedary Camel. J. Appl. Anim. Res. 1(1): 43-50

Shehada, N. (2011). 'Statistical Analysis in Geography and Social Sciences', (First Edition). Amman, Jordan: Dar Safaa Publishing and Distribution.

Swahn, M. H., Palmier, J. B., Kasirye, R., \& Yao, H. (2012) 'Correlates of suicide ideation and attempt among youth living in the slums of Kampala', International Journal of Environmental Research and Public Health, 9(2), 596-609.

Wasana, H. M., Aluthpatabendi, D., Kularatne, W. M. T. D., Wijekoon, P., Weerasooriya, R., \& Bandara, J. (2016) ‘Drinking water quality and chronic kidney disease of unknown etiology (CKDu): synergic effects of fluoride, cadmium and hardness of water',Environmental Geochemistry and Health, 38(1),157-168. 


\section{APPENDIX A}

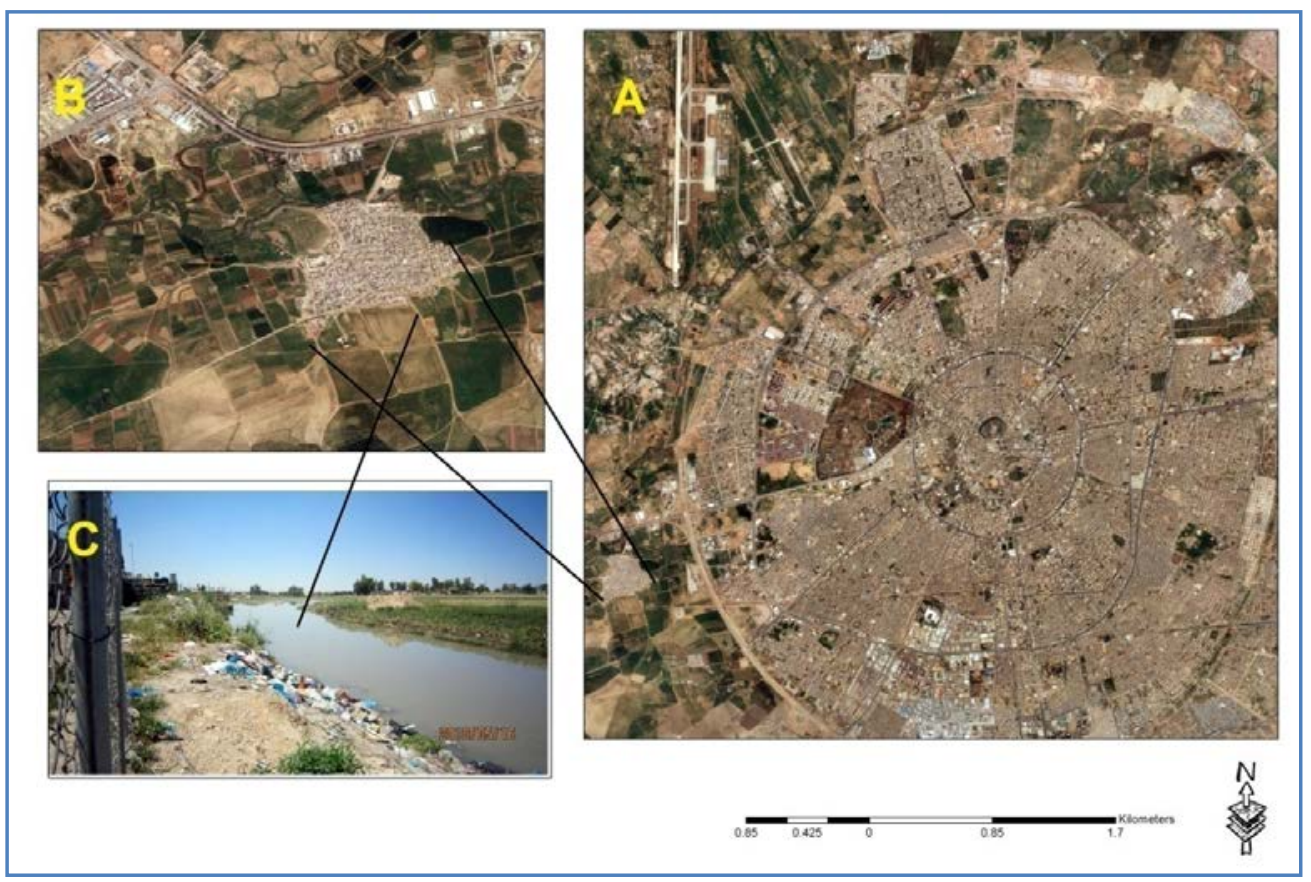

APPENDIX B

\begin{tabular}{|c|c|c|c|c|}
\hline \multicolumn{5}{|c|}{ Questionnaire } \\
\hline \multicolumn{5}{|c|}{ First: Questions about the characteristics of drinking water } \\
\hline 1-Source of drinking water: & $\begin{array}{c}\text { Special wells } \\
(1)\end{array}$ & $\begin{array}{c}\text { Public wells } \\
(\text { ) }\end{array}$ & $\begin{array}{c}\text { Project water } \\
(\text { ) }\end{array}$ & $\begin{array}{c}\text { Tank water } \\
(\quad)\end{array}$ \\
\hline \multicolumn{3}{|c|}{ 2- Is there a leak on the pipes? } & Yes( ) & No( ) \\
\hline $\begin{array}{l}\text { 3- If there is a switching } \\
\text { period? }\end{array}$ & 6 Months ( ) & 1 year( ) & 2 years ( ) & Above 3( ) \\
\hline \multicolumn{2}{|c|}{ 4- How long have you used the filter? } & 5 years( ) & Under 10( ) & Above 10( ) \\
\hline $\begin{array}{l}\text { 5- How old is the water } \\
\text { network? }\end{array}$ & 1 year( ) & 3 years ( ) & 5 years( ) & Above 5( ) \\
\hline \multicolumn{3}{|c|}{ 6- Do you feel the taste of chlorine in the water? } & Yes( ) & No( ) \\
\hline \multicolumn{3}{|c|}{ 7- Do you feel the taste of salts? } & Yes( ) & No( ) \\
\hline 8- Do you feel the follov & cteristics change? & Color( ) & Odor( ) & Taste( ) \\
\hline \multicolumn{4}{|c|}{ 9- If yes, the time period? } & 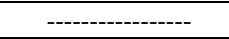 \\
\hline \multicolumn{3}{|c|}{ 10- Is the water tank washed? } & Yes( ) & No( ) \\
\hline \multicolumn{4}{|c|}{ 11- The number of washing times per year? } & $(1)$ \\
\hline \multicolumn{5}{|c|}{ Second: questions about some diseases } \\
\hline 1- Do family members $h$ & llowing diseases? & Kidney weakness( ) & $\begin{array}{c}\text { Kidney stones } \\
(1)\end{array}$ & $\begin{array}{c}\text { Kidney sand } \\
(1)\end{array}$ \\
\hline \multicolumn{4}{|c|}{ 2- If yes, what is the age of the patient? } & $(1)$ \\
\hline \multicolumn{5}{|c|}{\begin{tabular}{l|l} 
3- Are there any cases? & \\
\end{tabular}} \\
\hline $\begin{array}{l}\text { 4- Where was the } \\
\text { treatment? }\end{array}$ & $\begin{array}{c}\text { At home } \\
(1)\end{array}$ & $\begin{array}{c}\text { In hospital } \\
(1)\end{array}$ & $\begin{array}{c}\text { Private clinic } \\
(1)\end{array}$ & $\begin{array}{c}\text { Government clinic( } \\
\text { ) }\end{array}$ \\
\hline \multicolumn{5}{|c|}{ Third: Questions related to environmental culture } \\
\hline \multicolumn{3}{|c|}{ 1- Did you know the type of salt that is mixed with water? } & Yes( ) & No( ) \\
\hline \multicolumn{3}{|c|}{ 2- Is the water in the area safe to drink? } & Yes( ) & No( ) \\
\hline \multicolumn{3}{|c|}{ 3- Have specialists visited governmental institutions? } & Yes( ) & No( ) \\
\hline
\end{tabular}

